\section{Culture, neutrality and minority rights}

\section{Aurélia Bardon}

University College London, UK
European Journal of Political Theory 2018, Vol. 17(3) 364-374

(C) The Author(s) 2015 Reprints and permissions: sagepub.co.uk/journalsPermissions.nav DOI: $10.1177 / 1474885115596694$ ept.sagepub.com

Alan Patten, Equal Recognition: The Moral Foundations of Minority Rights. Princeton University Press: Princeton, 2014; 327 pp. \$45.00 (hbk).

\begin{abstract}
Alan Patten's Equal Recognition offers a new and powerful argument to support the 'strong cultural rights thesis'. Unlike other culturalist arguments, his argument is not based on a problematic and essentialist conception of culture but on a particular understanding of liberal neutrality as fair treatment and equal recognition. What justifies the existence of such rights is not culture itself but what culture means for people and the negative consequences it can have for them when they form a cultural minority. Patten's argument, however, faces another challenge: I argue that culture and neutrality cannot be fully reconciled, and that, ultimately, the concept of culture might not be playing any significant role in his argument for minority rights.
\end{abstract}

\title{
Keywords
}

Culture, neutrality, fair treatment, equal recognition, minority rights, liberal culturalism

In Equal Recognition, Alan Patten resuscitates the debate on culture and minority rights in liberalism. The debate dominated political philosophy in the 1990s and 2000s (see notably Gutmann, 2003; Kukathas, 2005; Kymlicka, 1989, 1995, 2001; Kymlicka and Patten, 2003; Phillips, 2007; Taylor, 1992; Young, 1990). Two camps were opposed. On the one hand, multiculturalists denounced the hypocrisy of difference-blind neutrality and insisted that cultures should be recognised, protected and preserved, and therefore that cultural rights were necessary. This camp included both communitarians such as Taylor and liberal culturalists such as Kymlicka, who reconcile liberalism and cultural rights through the liberal values of freedom and equality. On the other hand, nonculturalist liberals responded that liberalism already had the relevant

\section{Corresponding author:}

Aurélia Bardon, University College London, School of Public Policy, 29-3I Tavistock Square, London WCIH 9 QU, UK.

Email: a.bardon@ucl.ac.uk 
normative resources to justify certain rights or accommodations in specific conditions when they were required to guarantee equal and fair opportunities of all individuals, but that there was no need to refer to the problematic concept of culture or to controversial ideas of the role of culture in individuals' life (Appiah, 2005; Barry, 2001). Patten's book provides a powerful and innovative argument that breaks those lines: he refuses to choose between liberal neutrality and cultural rights and instead argues that cultural rights are in fact justified by a certain conception of liberal neutrality.

Although Patten is 'very sympathetic with Kymlicka's theory of cultural rights' (Patten, 2014: 5), he believes that there is a need for a restatement of liberal culturalism because it lacks a firm moral foundation (Patten, 2014: 8). There are two main differences between Patten's argument and liberal culturalism. First, Patten argues that liberal neutrality provides the moral foundation needed to justify cultural rights. Whereas Kymlicka argues that 'the idea that the government could be neutral with respect to ethnic and national groups is patently false' (Kymlicka, 1995: 110-111), Patten claims that the liberal state 'can, in principle at least, be neutral between majority and minority cultures' (Patten, 2014: 27). Second, Patten is more critical than liberal culturalists towards the idea that cultural rights and nationalism can be reconciled. Liberal culturalists, including Kymlicka, believe that nation-building is compatible with liberalism, and that liberal states can, within certain limits, favour one particular national culture over others (Patten, 2014: 172-173). Patten recognises that the liberal requirement for neutrality towards culture does not always outweigh the claims of liberal nationalists (Patten, 2014: 176), but he argues that such considerations are highly context dependent and that cultural rights can be seen as setting limits on liberal nationalism (Patten, 2014: 177).

I start with a reconstruction of Patten's very complex argument for strong cultural rights (1-4). I then focus on what I take to be the main challenge for Patten: I do not think that culture and neutrality can be fully reconciled, and ultimately the concept of culture might not be playing any significant role in his argument for minority rights (5).

\section{I.}

Culture is a problematic term for liberals. It does not fit easily with the liberal understanding of a society or of an individual. Classical liberals have for a long time avoided the problem and assumed that liberal neutrality and equal treatment of all would be enough to manage cultural diversity and to actually make everyone free and equal. But the problem persisted and it became obvious that a more direct political solution was necessary.

In certain cases, it seems that the solution does require granting minority rights. This is not really the object of disagreements among liberals anymore: culturalist and nonculturalist liberals alike would in many cases agree on what should be done. The main disagreement is about the justification of this solution. Patten's introductory chapter clarifies the terms of this disagreement by identifying four distinctions between culturalist and nonculturalist claims about minority rights: it opposes principled and pragmatic reasons, basic and derivative considerations, minority-regarding 
and third-party-regarding or impersonal reasons, and permissible and required policies (Patten, 2014: 11-24). Patten's claim is that 'there are basic reasons of principle for thinking that certain policies of recognition and accommodation are owed to cultural minorities as such' (Patten, 2014: 11). However, he immediately and significantly softens this claim by adding that it remains context dependent: it will be more or less robust in different situations, depending on the background context.

Patten's argument for strong cultural rights is based on two concepts: culture and neutrality. A specific understanding of what culture is and why it matters (Chapters 2 and 3), followed by a specific understanding of what neutrality means and how it is realised (Chapters 4 and 5), leads to the defence of minority rights under particular conditions (Chapters 6,7 and 8). The argument is highly sophisticated and it is necessary to look at each of these three different steps in more detail.

\section{2.}

Patten makes three important claims about (i) the definition of culture, about (ii) why it might be problematic if a culture is disappearing and about (iii) the special character of cultural commitments.

Culture is defined as a set of formative conditions and not as a set of specific beliefs or values: it is 'what people share when they have shared subjection to a common formative context' (Patten, 2014: 39). This definition is then significantly different from the essentialist and preservationist conception used by multiculturalists: Patten recognises that cultures evolve, that there can be high degrees of heterogeneity and that what makes the identification of distinct cultures possible is not their specific contents but the ways in which contents are transmitted. Control is key for the survival of a culture. In the absence of control over the socialisation of future generations, the transmission of the culture is 'disrupted' (Patten, 2014: 47). Since culture is understood as social lineage, disruption in the transmission amounts to cultural loss. It is precisely this control that is being denied when a culture is a minority and when the majority culture is the only one benefitting from recognition. This definition allows Patten to distance himself from the problematic, essentialist and preservationist conception of culture usually referred to by culturalist liberals. Based on the social lineage account of culture, cultural rights should aim at giving cultural minorities more control over socialisation, not at recognising directly specific values or beliefs: cultural rights, then, do not necessarily lead to the freezing of cultures. This makes Patten's definition of culture evaluatively better than the essentialist alternative. The essentialist account of culture is problematic because it is incompatible with the idea that a culture can evolve over time and because it assigns a value to cultures independently of the types of beliefs that might be characteristic of a culture, including illiberal beliefs (Patten, 2014: 42). Besides, this definition of cultures as sets of formative conditions is empirically much more convincing: it does not imply that people sharing a culture will also necessarily share specific beliefs, or that people who do not share the same culture cannot actually share many values.

To justify the need for cultural rights, it is not enough to show that it is possible to identify distinct cultures without falling into essentialism, it is also necessary to 
explain why culture as a social lineage matters. Cultural loss is associated with specific disadvantages: individuals who share this culture are burdened because they lack access to the majority culture's option, or because the options they have access to are not adequate. A close analysis of these arguments, however, shows that such disadvantages cannot provide a firm basis for cultural rights: cultural loss in itself is not enough. Instead, Patten argues that cultural rights are justified when this cultural loss is the result of an unfair treatment of cultures. In other words, all citizens have a right to fair treatment of their cultures, but they do not have a right to cultural preservation in general.

But why should there be a fair treatment of cultures in the first place? It is because, Patten suggests, cultural commitments are special. This last claim about culture is not as carefully or lengthily developed as the first two. It is, however, a necessary step between his account of culture and his account of neutrality to justify that cultures should be treated in a fair and neutral manner. An explanation can be reconstructed based on two important points mentioned by Patten. First, although culture cannot be in itself considered as a conception of the good, it does play a significant role in the shaping of people's conceptions of the good, and it will be part of the conception of the good of many individuals that their own culture should survive (Patten, 2014: 159). Second, within conceptions of the good, cultural commitments play a particular role, a special role, and neutrality is even more justified when it comes to such special commitments (Patten, 2014: 136). Patten identifies three factors that can contribute to the special character of commitments. A commitment is special when it plays a pivotal role 'in a whole set of a person's ends' (Patten, 2014: 133). This means that other preferences will depend on the realisation of this particular commitment. A second factor is that it has a nonnegotiable character: it is not the kind of commitment that one might trade against others. Finally, a commitment is special when it has recognitional salience, i.e. when the impossibility of realising a particular commitment would send 'an unjustifiably disparaging and exclusionary message' (Patten, 2014: 135) to those holding this commitment. There is, of course, no perfect overlap between cultural and special commitments: not all special commitments are about culture, and not all cultural commitments will be considered as special by the individual holding them. Patten, however, claims that the 'cultural aspects of a person's conception of the good often possess one or more of these features, and thus persons normally have a weighty interest in being able to fulfill their cultural values' (Patten, 2014: 29). For this reason, we should expect neutrality to be uneasily overridden by other political values when it comes to religion, conscience or culture.

\section{3.}

The concept of neutrality is characterised by four claims regarding (i) its proper meaning, (ii) its justification (why should we be committed to neutrality in the first place), (iii) its domain (what precisely should the liberal state be neutral toward?) and (iv) the ways in which it can be achieved (how do we actually realise neutrality?). 
Patten's first claim about neutrality is that it should be understood as neutrality of treatment, not as neutrality of effects or neutrality of intentions. What matters here is not that policies are neutrally justified, or that they have equal consequences for all, but that they are not 'more accommodating of some conceptions of the good than they are of others' (Patten, 2014: 115). Neutrality of effects is rejected as being impossible, and neutrality of intentions, or justificatory neutrality, is rejected because neutral reasons can be used to justify unfair policies. Instead of focusing on the intentions or on the consequences, Patten focuses on the policies themselves: a policy is neutral if it does not by itself provide a form of assistance to particular conceptions of the good and not to others. Neutrality of treatment does not fall back into neutrality of effects because the only kind of effect it focuses on is 'the direct effect that a policy has on making a conception of the good more or less realizable' (Patten, 2014: 116), and not any kind of direct or indirect effect that a policy might have on the success of a conception of the good.

But why should this be the case and why is fair treatment necessary? Neutrality is justified by other liberal commitments: it is a 'downstream value' (Patten, 2014: 108). Liberals are committed to neutrality not because neutrality is good in itself, but because liberals are already committed to the values of self-determination and equal consideration, which are themselves nonneutral. Self-determination is an interest that all individuals have in having the opportunity to develop and realise their conception of the good. Three types of considerations make self-determination a very important interest: it is closely related to well-being, it is intrinsically valuable and the conceptions of the good that people hold contain special commitments (Patten, 2014: 131-136). Besides, liberals believe that the state should give equal consideration to the interests of all citizens, and therefore all citizens should have a fair opportunity for self-determination (Patten, 2014: 127). Consequently, the liberal state has an important responsibility to guarantee that all individuals have a fair opportunity to live according to their own conceptions of the good, especially when it involves special commitments, and this requires that such conceptions of the good and special commitments be treated neutrally.

It follows from the previous point that neutrality only applies to a specific domain. It applies to conceptions of the good, because conceptions of the good are at the heart of self-determination, but it does not apply to all conceptions of the good, and more specifically it does not apply to conceptions of the good that would reject the value of self-determination: illiberal and worthless conceptions are consequently and justifiably excluded from the domain of neutrality (Patten, 2014: 109). Because neutrality is a downstream value, it also follows that the state only has a 'defeasible, or pro tanto, reason to be neutral' (Patten, 2014: 111), and that this reason to be neutral will be partly dependent on the type of preferences that are at stake: departures from neutrality are always possible, but they are less easily justified for special commitments than for superficial preferences or expensive tastes.

Finally, and more importantly, Patten identifies three ways in which neutrality of treatment can be realised: privatisation, generic entanglement and evenhandedness (Patten, 2014: 119). Privatisation and generic entanglement are both forms of nonrecognition (Patten, 2014: 169), i.e. cases in which there is no unfair accommodation of 
any conception of the good, whereas evenhandedness corresponds to equal recognition: 'two or more cultures (or religions, etc.) are equally recognized when a comparable form of customized assistance is extended to each of them' (Patten, 2014: 161). Privatisation is the extreme form of nonrecognition, and therefore the only way to fully realise neutrality. The two other strategies can only approximate the ideal of neutrality. Generic entanglement describes the entanglement of the state in the provision of goods and activities that are beneficial for all conceptions of the good, such as the 'state's provision of police, fire, and school-bus services' (Patten, 2014: 121). All conceptions of the good that are part of the domain of neutrality benefit equally from generic entanglement, and therefore it is neutral. Finally, evenhandedness describes a direct but equal involvement of the state in the recognition of several conceptions of the good: the state provides assistance for goods or activities that are specific to particular conceptions of the good, but it does so in an equal way, providing similar assistance for other goods and activities that are also considered important in other conceptions of the good.

Nonrecognition is not always available as a strategy to realise neutrality. This is precisely where the problem with culture comes from: because the state needs to recognise a particular culture and a particular language (Patten, 2014: 169), it cannot opt for nonrecognition. Majoritarian recognition of a single culture, when there are cultural and linguistic minorities, is nonneutral: it accommodates a particular culture more than others, which amounts to a breach of neutrality and of the liberal commitment to provide fair opportunities for self-determination. Equal recognition, it follows, is the only available strategy to realise cultural neutrality in cases where privatisation and generic entanglement are impossible.

\section{4.}

Whenever there is cultural diversity in a society, and when the state is failing to extend equal recognition to cultural minorities, then these minorities have a principled, but defeasible, complaint about this situation. This complaint will be balanced with other legitimate political objectives, but in certain cases it will justify not only that cultural rights should be granted, but also that they should be granted as a matter of justice. Patten applies this argument for strong but contextdependent cultural rights to two areas well known in the multiculturalist literature: linguistic rights and self-government rights.

Language, like culture, is an especially weighty preference because it is related to identity. In cases of official monolingualism, when one single language is recognised by the state, minority languages fare poorly because of this unequal recognition, and this directly affects the conceptions of the good that members of these minorities hold. Patten defends a model of 'prorated official multilingualism' (Patten, 2014: 200), where comparable forms of assistance are extended to different languages. The promotion of minority languages by the state is 'prorated' because its aim is neither the preservation of minority languages nor the equal treatment of all languages. It does not entail, for instance, that the state should stop expressing itself through the majoritarian language, but rather that speakers of a minority language have the opportunity to send their children to a school where instruction 
is provided in this minority language, or to use this minority language when they have to deal with public institutions.

In certain cases, equal recognition does not lead only to linguistic rights but to rights of self-government. Siding with Allen Buchanan's remedial rights only theory, Patten denies that there can be a 'right to secede from a flawless state' (Patten, 2014: 235). He extends Buchanan's argument, however, by adding failure of recognition to the list of injustices that would justify this right. Equal recognition, in this case, refers to the enjoyment of self-government rights and requires the existence of a democratic forum for each of the national minorities within the political community (Patten, 2014: 240).

But to which groups exactly are such language rights and rights of selfgovernment owed? Hundreds of cultural groups coexist in contemporary societies, and it would seem like a very serious practical issue if equal recognition had to be extended to all of them. Patten's response is based on a distinction between immigrants and national minorities. This distinction is justified by a new conception of the voluntary acceptance theory: immigrants are assumed to consent to a special kind of burden, including the waiving of cultural rights. This however only applies to first-generation immigrants and not to their descendants who have not themselves made any decision to emigrate and who therefore haven't waived their cultural rights. Although Patten does not explicitly say that descendants of immigrants should be treated as national minorities, he argues that they 'should not themselves be thought of as immigrants, and their claims to cultural rights should be analyzed in a different way' (Patten, 2014: 276).

\section{5.}

In many regards, Patten's argument for strong cultural rights is more persuasive than the alternative arguments in the liberal culturalist camp. It avoids the overly controversial essentialist conception of culture and it convincingly defends the idea that the concept of neutrality also applies to culture. But the reconciliation of culture and neutrality is not as successful as one might have hoped.

To make the argument about minority rights without relying on a problematic conception of culture, Patten needs to take a long detour through selfdetermination, identity-related claims, cultural loss and equal responsiveness to all interests. His ambition in doing so is twofold: distancing himself from essentialist and preservationist accounts of cultures, without abandoning the possibility of justifying cultural rights. But because he insists so much that the objective of equal recognition is fairness towards individuals rather than towards cultures as such, one ends up wondering which part the concept of culture actually plays in his argument and, consequently, whether the category of cultural rights is normatively relevant. Ultimately, to the extent that his argument has normative force, it seems that it might be independently of the concept of culture itself and Patten's argument might end up being closer to the nonculturalist position than he claims.

The traditional culturalist defence of minority rights is based on the idea that cultures are intrinsically valuable: cultural loss is then problematic in itself, and the 
objective of cultural rights is to guarantee the preservation of the culture. In other words, the preservationist account of culture is a sufficient basis for the justification of cultural rights. But Patten rejects this account of culture: what is then left for him to justify cultural rights? Recall that his argument is developed in two steps, first with a new conception of culture and then with a new conception of neutrality. Each conception on its own might be challenged; but the most problematic part of the argument seems to be in the relation between these two concepts. Because he rejects the preservationist account of culture, Patten needs a new foundation for cultural rights: this new foundation is neutrality as fair treatment. To defend cultural rights, Patten then also needs to provide a good explanation as to why there should be neutrality towards culture in the first place, and why the concept of neutrality should justify cultural rights in any special way.

The suggestion that neutrality applies to culture because cultural commitments are special is problematic. The concept of culture is here both underinclusive and overinclusive. It is underinclusive because liberal neutrality does not apply only to culture, but more generally to all conceptions of the good (Patten, 2014: 104). We should therefore expect Patten's neutrality as fair treatment to apply to culture in the exact same way that it should apply to any other potential element of reasonable conceptions of the good, for instance religious beliefs or ethical commitments. Although both religious beliefs and ethical commitments can sometimes be cultural, in the sense that they can be associated with a particular social lineage and that they can be part of what is shared by a cultural group and transmitted to the next generation, this is not necessarily the case. Besides, the application of neutrality of treatment to all reasonable conceptions of the good might have some problematic implications. This would entail, for instance, that creationism should be taught alongside evolution theory in schools, since both are part of the domain of neutrality and, following Patten's argument, it would be unfair to accommodate conceptions of the good that give priority to scientific understandings of the world more than conceptions of the good that give priority to religious understandings of the world.

The concept of culture is also overinclusive since, without a controversial preservationist or essentialist conception, it cannot be assumed that culture always plays an important role in people's conceptions of the good, or that cultural loss will always be associated with a significant burden or disadvantage. So Patten's argument is neither exclusively valid for culture, nor always valid for culture; and his focus on culture therefore appears more arbitrary than his ambitious culturalist claims might suggest. Culture in Equal Recognition becomes a mere object of application of a neutrality argument rather than a core element in a culturalist argument. The justification for granting recognition rights is based on the existence of unfair opportunities for self-determination, and it is not clear why this would have anything to do with culture in particular. In fact, Patten seems to acknowledge that neutrality is not more required for culture than it is for other important parts of individuals' conceptions of the good when he writes that 'neutrality of treatment is [...] especially robust when it applies to aspects of conceptions of the good that involve religion and conscience, culture, family, sexuality, artistic endeavor, and other goods that are likely to seem non-negotiable to the individual' (Patten, 2014: 136). Culture is only 
one of the different things that should be treated neutrally by the liberal state, and the justification for the requirement of neutral treatment is not directly about culture itself.

Ultimately, Patten cannot avoid a standard dilemma regarding the justification of the protection of culture: either culture should be protected as such independently of how people relate to it, or it should not be protected as such because what we actually want to protect is whatever matters to people. The first strategy unfairly singles out culture as being particularly worth of protection and therefore clashes with neutrality of treatment: special treatment of culture means that other commitments that are similar and might be considered as special commitments will not be protected because they are not about culture, so cultural commitments are accommodated more than other noncultural but equally important commitments. The second strategy leads to an argument of equal treatment without appealing to the concept of culture: if the defence of minority rights is based on self-determination and neutrality towards what people care about, then there cannot be special cultural rights, i.e. cultural rights are simply part of a larger category of the right of fair opportunity to self-determination. Culture is not special in the sense that what justifies the neutral treatment of culture is not something necessarily associated with culture (since not every cultural commitment is a special commitment), nor something uniquely associated with culture (since not every special commitment is a cultural commitment). This second position is egalitarian: all valuable commitments that people might have will be treated in the same way, provided they are comparable or of similar importance.

The first strategy is a possible argument for culturalists, but Patten turns it down claiming that culture, on its own, cannot justify the need for protection. For Patten, however, the distinction between these two strategies is not the relevant one to distinguish him from his adversaries. In fact, he fits in the broad category of egalitarianism along with nonculturalist liberals such as Brian Barry: all share the second strategy. The relevant distinction for him is based on whether one believes that there are basic, nonderivative, liberal reasons 'for thinking that cultural minorities as such are owed particular forms of accommodation and recognition as a matter of principle' (Patten, 2014: 10). For Patten, nonculturalist liberalism cannot support this strong cultural rights thesis, and therefore there is a need for 'the liberal-culturalist idea that certain minority cultural rights are, as such, a requirement of liberal justice' (Patten, 2014: 10). This idea is thus identified by Patten as a way to distinguish between culturalist and nonculturalist versions of liberalism.

But it is not clear that Patten has the philosophical resources to hold this distinction: either he needs a stronger conception of culture that would by itself justify that minority rights are required by justice, or he cannot maintain the distinction because minority rights in nonculturalist arguments can also be required by justice. In fact, this is what Barry has claimed:

It is sometimes suggested that the individualistic nature of liberalism precludes any policies that provide special benefits for people on the basis of their membership in some group. While this may be true of liberalism in some forms, it is certainly not true 
of the egalitarian liberalism that provides the premises for this book. According to this, any disadvantage for which the victim is not responsible establishes a prima facie claim to remedy or compensation. The implication is that special measures to help the disabled are fully justified - and indeed required by justice - as a way of compensating for disadvantage. (Barry, 114; my emphasis)

Patten could then respond that in Barry's case, cultural rights might be required by justice but that they are not justified as such, i.e. as cultural rights. But why wouldn't the same objection apply to Patten himself? The difficulty in Patten's argument comes from the fact that he wants to reconcile an egalitarian approach in which justification of minority rights is based on neutrality instead of culture, with a conception of culture that would be strong enough to support the idea of cultural justice. But Patten lacks a justification for this cultural specialness: culture as a social lineage is a more convincing account than culture as a good in itself, but it does not provide a basis for special treatment. Like nonculturalist egalitarians, Patten justifies cultural rights with an appeal to neutrality and fairness rather than with an appeal to culture: how could there be any meaningful understanding of a cultural justice if what we ultimately want to protect is not culture itself but fair opportunities for self-determination?

This does not suggest that there are no important differences between Patten and Barry, especially regarding what culture is, why it matters and what kinds of disadvantages require compensation. But unless Patten shows that culture always necessarily matters, and that it matters in a special way that distinguishes it from other identity-related or special commitments regarding for example religion or sexuality, it is not clear why his argument is not in fact very close to nonculturalist egalitarianism.

\section{Declaration of conflicting interests}

The author(s) declared no potential conflicts of interest with respect to the research, authorship, and/or publication of this article.

\section{Funding}

The author(s) disclosed receipt of the following financial support for the research, authorship, and/or publication of this article: Research for this review article was funded by European Research Council (ERC) Grant 283867 on “Is Religion Special?”.

\section{References}

Appiah A (2005) The Ethics of Identity. Princeton: Princeton University Press.

Barry B (2001) Culture and Equality: An Egalitarian Critique of Multiculturalism. Cambridge: Polity.

Gutmann A (2003) Identity in Democracy. Princeton: Princeton University Press.

Kukathas C (2005) The Liberal Archipelago: A Theory of Diversity and Freedom. Oxford: Oxford University Press.

Kymlicka W (1989) Liberalism, Community, and Culture. Oxford: Oxford University Press. Kymlicka W (1995) Multicultural Citizenship: A Liberal Theory of Minority Rights. Oxford: Oxford University Press. 
Kymlicka W (2001) Politics in the Vernacular: Nationalism, Multiculturalism, and Citizenship. Oxford: Oxford University Press.

Kymlicka W and Patten A (2003) Languages Rights and Political Theory. Oxford: Oxford University Press.

Patten A (2014) Equal Recognition: The Moral Foundations of Minority Rights. Princeton: Princeton University Press.

Phillips A (2007) Multiculturalism Without Culture. Princeton: Princeton University Press.

Taylor C (1992) The politics of recognition. In: Gutmann A (ed.) Multiculturalism: Examining the Politics of Recognition. Princeton: Princeton University Press.

Young IM (1990) Justice and the Politics of Difference. Princeton: Princeton University Press. 